\title{
Analisis Perpindahan Panas dan Exergi pada Boiler Wanson I Tipe Fire Tube
}

\author{
Eflita Yohana $^{\mathrm{a},}$ *, MSK Tony Suryo ${ }^{\mathrm{a}}$, Iqbal Ambari ${ }^{\mathrm{b}}$, Randa Permana ${ }^{\mathrm{b}}$, Novi Laura Indrayanic \\ ${ }^{\mathrm{a}}$ Dosen Departemen Teknik Mesin, Fakultas Teknik, Universitas Diponegoro \\ ${ }^{b}$ Mahasiswa Departemen Teknik Mesin, Fakultas Teknik, Universitas Diponegoro \\ Jl. Prof. Sudharto, SH., Tembalang-Semarang 50275, Telp. +62247460059 \\ ${ }^{\mathrm{C}}$ Dosen Teknik Mesin, Universitas Islam 45 Bekasi \\ Jl. Cut Meutia No. 83 Bekasi Timur \\ *E-mail: efnan2003@gmail.com
}

\begin{abstract}
The boiler comprises a vessel that is sealed at its base end and is provided with a fire pipe and a water pipe as a medium of heat exchange from high to low and produces a pressurized vapor in the subsequent process to produce vapor with certain temperature and pressure. The vapor produced by the boiler on saturated vapor is used as a heating working fluid and the fractionation process. The purpose of this research is to know the energy efficiency of the boiler and the rate of heat transfer that occurs in the furnace of the boiler as well as to know the exergency efficiency and exergy loss from the wanson boiler 1 type fire tube. The method of this study is mathematical analysis using the general equations of heat transfer and exergy to calculate the efficiency and exergy loss. In the furnace there is radiation heat transfer of $1942.40 \mathrm{kWatt}$, conduction 1942,40 kWatt, convection 12448,41 kWatt while heat transfer that occurs in boiler fire pipe there is 160,58 kWatt radiation, 160,58 kWatt by conduction and 101.46kWatt. From this result known heat accumulation occurs in convection heat transfer process. While efficiency of boiler based on direct and indirect calculation is $70 \%$ and $82 \%$. While the result of the exergic analysis resulted the combat exergy loss of $1148.1627 \mathrm{~kJ} / \mathrm{s}$, the efficiency of the combustor exergy of $22.88 \%$ the loss and efficiency of the heat exchanger is 672.126 $\mathrm{kJ} / \mathrm{s}$ and $44.21 \%$ while the loss and efficiency of the whole boiler is $1820.286 \mathrm{~kJ} / \mathrm{s}$ and $13.29 \%$. It can be concluded that wanson 1 boiler is in good condition because it has high efficiency which is $70 \%$ and $82 \%$ which is calculated based on mathematical analysis directly and indirectly using heat balance but in boiler furnace there is heat accumulation of $59.12 \mathrm{kWatt}$. While the exergy analysis obtained efficiently from the boiler of $13.29 \%$
\end{abstract}

Keywords: Boiler; Heat Transfer; Exergi; Efficiency.

\begin{abstract}
Abstrak
Boiler terdiri dari vessel yang tertutup pada ujung pangkalnya dan dilengkapi dengan pipa api dan pipa air sebagai media pertukaran kalor dari tinggi ke rendah dan menghasilkan uap bertekanan pada proses selanjutnya untuk memproduksi uap dengan temperature dan tekanan tertentu. Uap yang dihasilkan oleh boiler pada uap saturated digunakan sebagai fluida kerja pemanas dan proses fraksinasi. Tujuan dilakukannya penelitian ini adalah untuk mengetahui besar efisiensi energi dari boiler dan besar laju perpindahan panas yang terjadi pada furnance dari boiler serta mengetahui besar efisiensi exergi dan rugi exergi dari boiler wanson 1 tipe fire tube. Metode penelitian ini adalah analisa secara matematis menggunakan persamaan umum perpindahan panas dan exergi untuk menghitung besar efisiensi dan kerugian exergy. Pada furnance terjadi perpindahan panas secara radiasi sebesar 1942,40 kWatt, konduksi 1942,40 kWatt, konveksi 12448,41 kWatt sementara perpindahan panas yang terjadi pada pipa-pipa api boiler ada sebesar 160,58 kWatt secara radiasi, 160,58 kWatt secara konduksi dan 101.46kWatt. Dari hasil ini diketahui penumpukan kalor terjadi pada proses perpindahan panas secara konveksi. Sementara efisiensi dari boiler berdasarkan perhitungan langsung dan tidak langsung adalah sebesar $70 \%$ dan $82 \%$. Sementara dari hasil analisis exergi dihasilkan rugi exergi kombusternya $1148.1627 \mathrm{~kJ} / \mathrm{s}$, efisiensi eksergi kombusternya 22.88\% kerugian dan efisiensi dari heat exchanger adalah $672.126 \mathrm{~kJ} / \mathrm{s}$ dan $44.21 \%$ sementara kerugian dan efisiensi dari boiler keseluruhan adalah 1820.286 kJ/s dan 13.29\%. Dapat disimpulkan bahwa boiler wanson 1 dalam keadaan baik karena memiliki efisien yang masih tinggi yaitu sebesar $70 \%$ dan $82 \%$ yang dihitung berdasarkan analisa matematis secara langsung dan tidak langsung menggunakan neraca panas namun pada furnance boiler terjadi penumpukan kalor sebesar 59.12 kWatt. Sedangkan analisa exergi didapat efisien dari boiler sebesar13.29\%.
\end{abstract}

Kata kunci: Boiler; Perpindahan Panas; Exergi; Efisiensi. 


\section{Pendahuluan}

Boiler adalah bejana tertutup dimana panas pembakaran dialirkan ke air sampai terbentuk air panas atau steam. Air panas atau steam pada tekanan tertentu kemudian digunakan untuk mengalirkan panas ke suatu proses. Sistem boiler terdiri dari: sistem airumpan, sistem steam, dan sistem bahan bakar [1].

Sistem air umpan menyediakan air untuk boiler secara otomatis sesuai dengan kebutuhan steam. Sistem steam mengumpulkan dan mengontrol produksi steam dalam boiler. Pada keseluruhan sistem, tekanan steam diatur menggunakan kran dan dipantau dengan alat pemantau tekanan. Sistem bahan bakar adalah semua peralatan yang digunakan untuk menyediakan bahan bakar untuk menghasilkan panas yang dibutuhkan. Peralatan yang diperlukan pada sistem bahan bakar tergantung pada jenis bahan bakar yang digunakan pada sistem [2].

Air yang disuplai ke boiler untuk diubah menjadi steam disebut air umpan. Dua sumber air umpan adalah : (1) Kondensat atau steam yang mengembun yang kembali dari proses dan (2) Air makeup (air baku yang sudah diolah) yang harus diumpankan dari luar ruang boiler dan plant proses. Untuk mendapatkan efisiensi boiler yang lebih tinggi, digunakan economizer untuk memanaskan awal air umpan menggunakan limbah panas pada gas buang sehingga didapatkan efisiensi yang maksimal [2].

Tujuan penelitian ini adalah untuk mengetahui besar efisiensi energi dari boiler dan besar laju perpindahan panas yang terjadi pada furnance dari boiler serta mengetahui besar efisiensi exergi dan rugi exergi dari boiler wanson 1 tipe fire tube.

\section{Material dan metode penelitian}

\subsection{Data penelitian}

Penelitian ini berfokus kepada analisis perpindahan panas dan analisis eksergi boiler Wanson I. Lokasi penelitian bertempat di PPSDM Migas Cepu, Jawa Tengah. Boiler Wanson I merupakan boiler jenis pipa api dengan tekanan dan kapasitas rendah, berjumlah 1 unit yang berkapasitas $6600 \mathrm{~kg} / \mathrm{jam}$ dan jenisnya pipa api horizontal. Bahan bakar yang digunakan ada 3 jenis yaitu LPG, solar dan residu. LPG dan solar digunakan untuk penyalaan awal. Metode yang digunakan dalam melakukan analisis ini adalah dengan mengumpulkan data pengoperasian boiler Wanson 1 dan melakukan perhitungan matematis untuk mendapatkan hasil analisa.

Untuk lebih jelas spesifikasi dari Boiler Wanson 1 tipe fire tube di PPSDM Migas Cepu berikut dijelaskan pada Tabel 1 dibawah ini.

Tabel 1. Spesifikasi Boiler Wanson I

\begin{tabular}{ccc} 
No. & Karakteristik & Spesifikasi \\
\hline 1. & Tipe & Boiler fire tube \\
2. & Tekanan operasi & $2 \mathrm{~kg} / \mathrm{cm}^{2}$ \\
3. & Tekanan maksimal & $9 \mathrm{~kg} / \mathrm{cm}^{2}$ \\
4. & Kapasitas maksimum & $6,6 \mathrm{ton} / \mathrm{jam}$ \\
5. & Temperatur maksimal & $190^{0} \mathrm{C}$ \\
\hline
\end{tabular}

Untuk menyederhanakan dalam perhitungan, model dibuat dalam 3 sketsa dengan asumsi sebagai berikut.

a. Energi kinetik dan energi potensial didalam sistem diabaikan.

b. Nilai laju aliran steam dan feedwater yang terbuang di sistem blowdown dianggap nol.

c. Proses pembakaran di boiler dioperasikan secara adiabatik.

d. Flue gas dan heat product dimodelkan sebagai gas ideal. Dengan temperatur lingkungan $\mathrm{T}_{0}\left(\mathrm{~T}_{0}=25^{\circ} \mathrm{C}\right)$.

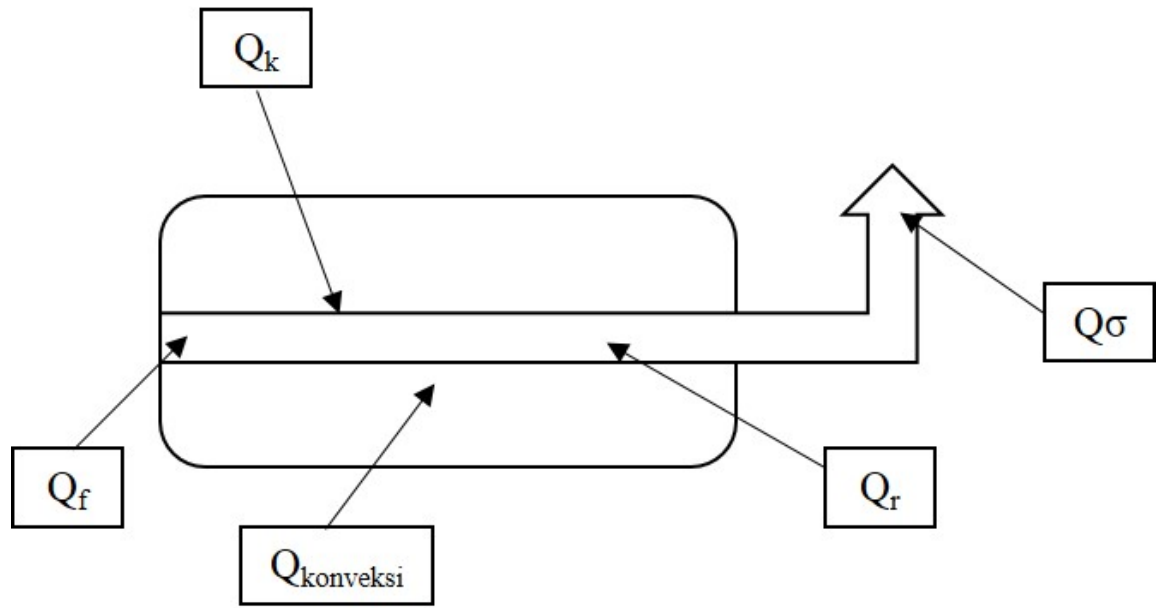

Gambar 1. Sketsa perpindahan panas boiler. 
Berikut data bahan bakar dari lab kilang PPSDM Migas Cepu pada Tabel 2.

Tabel 2. Data Bahan Bakar

\begin{tabular}{ccc} 
No. & Karakteristik & Spesifikasi \\
\hline 1. & Bahan bakar & Boiler fire tube \\
2. & Nilai kalor & $2 \mathrm{~kg} / \mathrm{cm}^{2}$ \\
3. & Temperatur nyala & $9 \mathrm{~kg} / \mathrm{cm}^{2}$ \\
4. & Berat bahan bakar & $6,6 \mathrm{ton} / \mathrm{jam}$ \\
5. & Total pemakaian bahan bakar & $173,787 \mathrm{liter} / \mathrm{jam}$ \\
\hline
\end{tabular}

Produksi Uap yang dihasilkan boiler ditampilkan pada Tabel 3.

Tabel 3. Produksi Uap

\begin{tabular}{ccc}
\hline No. & Karakteristik & Nilai \\
\hline 1. & Massa uap & $0.55 \mathrm{~kg} / \mathrm{s}$ \\
2. & Tekanan operasi & $3 \mathrm{~kg} / \mathrm{cm}^{2}$ \\
3. & Suhu uap & $130{ }^{0} \mathrm{C}$ \\
4. & Entalpi lanjutan & $2719 \mathrm{kj} / \mathrm{kg}$ \\
5. & Entalpi air umpan & $2790 \mathrm{kj} / \mathrm{kg}$ \\
\hline
\end{tabular}

\subsection{Persamaan2 yang digunakan}

Berdasarkan asumsi-asumsi di atas maka persamaan yang digunakan adalah sebagaimana tertera dibawah ini.

Panas masuk:

$\mathrm{Q}=\dot{\mathrm{m}} \mathrm{x}$ LHV (nilai kalor dari residu)

Panas sensible bahan bakar :

$\mathrm{Q}_{\mathrm{g}}=(1-\mathrm{W}) \times \mathrm{cp}_{\mathrm{f}} \times \mathrm{T}_{\mathrm{f}} \times \dot{\mathrm{m}}$

Panas yang dipindahkan dari gas menyala ke dinding dalam lorong api

$\mathrm{Q}_{\mathrm{r}}=\mathrm{Q}_{\mathrm{f}}-\mathrm{Q}_{\mathrm{g}}$

Laju perpindahan kalor radiasi dari nyala api ke dinding dalam lorong api :

$\mathrm{Q}=\boldsymbol{\sigma} \cdot \mathrm{A} \mathrm{T} \mathrm{T}^{4}$

Laju perpindahan kalor konduksi pada lorong api :

$Q_{k}=\frac{2 \Pi k L\left(T_{w i}-T_{w o}\right)}{\ln \left(r_{o}-r_{i}\right)}$

perpindahan kalor didih kolam :

$\mathrm{Q}_{\mathrm{d}}=\mathrm{h} \mathrm{A}\left(\mathrm{T}_{\mathrm{wo}}-\mathrm{T}_{\mathrm{j}}\right)$

dimana, $h=h_{1}\left[\frac{p}{p_{1}}\right]^{0,4}$

Besar kalor yang dihasilkan oleh air umpan saat mejadi uap air :

$\mathrm{Q}_{\text {uap }}=\mathrm{m}_{\mathrm{air}} \mathrm{C}_{\mathrm{p}} \Delta \mathrm{T}$

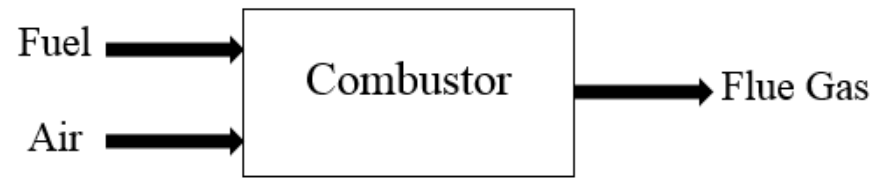

Gambar 2. Sketsa aliran eksergi combustor [4].

$$
\begin{aligned}
& \mathrm{X}_{\text {in }}-\mathrm{X}_{\text {out }}-\mathrm{X}_{\text {destroyed }}=\frac{\mathrm{dX}_{\text {system }}}{\mathbf{d t}}=\mathbf{0}==>\text { steady } \\
& \left(\mathrm{m}_{\mathrm{f}} \varepsilon_{\mathrm{f}}+\mathrm{m}_{\mathrm{g}}\right)-\mathrm{m}_{\mathrm{p}} \varepsilon_{\mathrm{p}}-\mathrm{I}_{\mathrm{C}}=0 \\
& \mathrm{I}_{\mathrm{C}}=\dot{m}_{\mathrm{f}} \varepsilon_{\mathrm{f}}+\dot{m}_{\mathrm{g}} \epsilon_{\mathrm{g}}-\dot{m}_{\mathrm{p}} \varepsilon_{\mathrm{p}}
\end{aligned}
$$


Kerugian eksergi pada combustor :

$\mathbb{I}_{\mathrm{C}}=\dot{\mathrm{m}}_{\mathrm{f}}\left(\mathrm{h}_{\mathrm{f}}-\mathrm{T}_{\mathrm{o}} \mathrm{s}_{\mathrm{f}}\right)+\dot{\mathrm{m}}_{\mathrm{g}}\left(\mathrm{h}_{\mathrm{a}}-\mathrm{T}_{\mathrm{0}} \mathrm{s}_{\mathrm{g}}\right)-\dot{\mathrm{m}}_{\mathrm{p}}\left(\mathrm{h}_{\mathrm{p}}-\mathrm{T}_{\mathrm{o}} \mathrm{s}_{\mathrm{p}}\right)$

Efisiensi eksergi pada combustor :

$$
\Psi_{\mathrm{C}}=\frac{\dot{m}_{\mathrm{p}} s_{\mathrm{p}}}{\dot{\mathrm{m}}_{\mathrm{f}} \varepsilon_{\mathrm{f}}}=\frac{\dot{\mathrm{m}}_{\mathrm{p}}\left(\mathrm{h}_{\mathrm{p}}-\mathrm{T}_{\mathrm{o}} s_{\mathrm{p}}\right)}{\dot{\mathrm{m}}_{\mathrm{f}}\left(\mathrm{h}_{\mathrm{f}}-\mathrm{T}_{\mathrm{o}} s_{\mathrm{f}}\right)}
$$

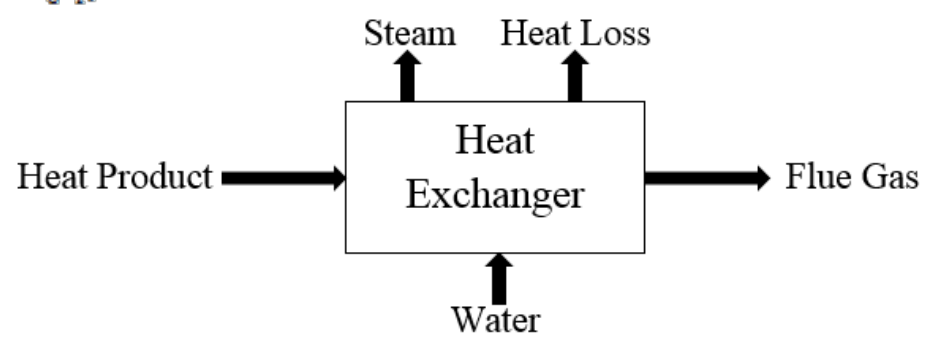

Gambar 3. Sketsa eksergi heat exchanger [4].

Kerugian eksergi pada heat exchanger :

$I_{H}^{x}=\dot{m}_{H}\left(h_{p}-T_{0} s_{p}\right)-\left(h_{g}-T_{0} s_{g}\right)+\dot{m}_{c}\left(h_{l}-T_{0} s_{l}\right)-\left(h_{s}-T_{0} s_{s}\right)$

Efisiensi eksergi pada heat exchanger :

$\Psi_{\mathrm{H}}=\frac{\mathrm{m}_{\mathrm{r}}\left(\varepsilon_{\mathrm{s}}-\varepsilon_{\mathrm{l}}\right)}{\mathrm{m}_{\mathrm{h}}\left(\varepsilon_{\mathrm{p}}-\varepsilon_{\mathrm{g}}\right)}$

Total kerugian eksergi pada boiler :

$\mathrm{I}_{\mathrm{B}}=\mathrm{I}_{\mathrm{C}}+\mathrm{I}_{\mathrm{H}}$

Total efisiensi eksergi pada boiler :

$$
\Psi_{\mathrm{B}}=\frac{\mathrm{m}_{\mathrm{r}}\left(\varepsilon_{\mathrm{s}}-\varepsilon_{\mathrm{V}}\right)}{\mathrm{m}_{\mathrm{f}} \varepsilon_{\mathrm{f}}}
$$

\section{Hasil dan Pembahasan}

\subsection{Analisa perhitungan perpindahan panas pada lorong api dan pipa pipa api boiler Wanson 1}

Besar heat transfer yang akan dihasilkan pada lorong api dan pipa api boiler Wanson 1 terdapat pada Tabel 4.

Tabel 4. Perpindahan panas pada lorong api dan pipa api boiler Wanson 1

\begin{tabular}{cll}
\hline No. & \multicolumn{1}{c}{ Karakteristik } & \multicolumn{1}{c}{ Nilai } \\
\hline 1. & Perpindahan panas dari bahan bakar $\left(\mathrm{Q}_{\mathrm{f}}\right)$ & $7002200 \mathrm{~kJ} / \mathrm{h}$ \\
2. & Panas gas asap dari bahan bakar residu ( Qg ) & $9525.25 \mathrm{~kJ} / \mathrm{h}$ \\
3. & Perpindahan panas secara radiasi ( Qr ) & $1942,40 \times 10^{3}$ Watt \\
\hline
\end{tabular}

Dengan diketahui laju radiasi ini kita dapat menentukan suhu dinding bagian dalam dari lorong api. Dimana temperatur nyala api pembakaran menghasilkan suhu mencapai $975^{\circ} \mathrm{C}$.

\subsubsection{Perpindahan Panas Radiasi, Konduksi, dan Konveksi}

Perpindahan panas secara radiasi pada boiler Wanson 1 terjadi pada pipa api dari nyala api pada burner dengan analisa dengan persamaan (4). Pada dinding luar kedalam dari furnance terjadi perpindahan panas secara konduksi antara dinding dalam dan luar dari lorong api dimana kita asumsikan bahwa $\mathrm{Q}_{\text {radiasi }}=\mathrm{Q}_{\text {konduksi }}=\mathrm{Q}_{\text {konveksi }}$ agar tidak terjadi penumpukan kalor pada lorong dan pipa api [5].

Berdasarkan persamaan (5) dan mengasumsikan bahwa antara dinding luar dan dalam dari lorong tidak terjadi penumpukan kalor temperatur dinding bagian luar dari lorong api (furnance) sehingga diasumsikan $\mathrm{Q}_{\text {radiasi }}=\mathrm{Q}_{\text {konduksi. }}$ Berdasarkan persamaan (5) didapat temperature dinding bagian luar dari lorong api (furnance) adalah sebesar $204,53{ }^{\circ} \mathrm{C}$ hal ini telah memenuhi ketentuan Property of saturated table yang menjelasakan bahwa pada saat tekanan 2 bar 
temperatur saturasinya adalah sebesar $120.2{ }^{\circ} \mathrm{C}$,sementara hasil yang didapat dari analisa perpindahan panas secara konduksi dari dinding luar adalah $204,53{ }^{\circ} \mathrm{C}$ hal ini sudah memenuhi untuk mengubah liquid menjadi saturated vapor.

Perpindahan panas terjadi secara konveksi antara dinding luar lorong api dengan air umpan boiler. Dapat dicari dengan menggunakan persamaan (7) dan (6). Karakteristik perpindahan panas secara radiasi, konduksi, dan konveksi terdapat pada Tabel 5.

Tabel 5. Perpindahan panas secara radiasi, konduksi, dan konveksi pada Boiler Wanson 1

\begin{tabular}{llcc}
\hline No. & Karakteristik & Suhu dinding (Tw) & Nilai \\
\hline 1. & Perpindahan Panas Radiasi & $343^{\circ} \mathrm{C}$ & $160,58 \times 10^{3} \mathrm{Watt}$ \\
2. & Perpindahan Panas Konduksi & $204.53^{0} \mathrm{C}$ & $160,58 \times 10^{3} \mathrm{Watt}$ \\
3. & Perpindahan Panas Konveksi & $203^{0} \mathrm{C}$ & $1014,63 \times 10^{3} \mathrm{Watt}$ \\
\hline
\end{tabular}

\subsection{Analisa Perpindahan Panas pada Air menjadi Uap}

Kurva perpindahan panas pada proses perubahan air menjadi uap pada boiler dapat dijelaskan pada Gambar 4 berikut ini.

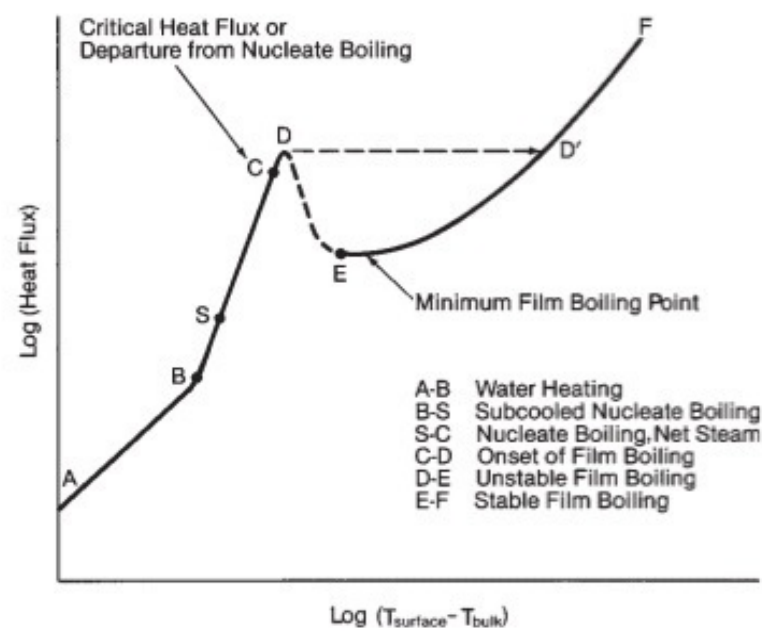

Gambar 4. Kurva perpindahan panas pada boiler [6].

Setelah menggalami pemanasan oleh pipa api tadi suhu air akan menjadi $133.6{ }^{\circ} \mathrm{C}$ sehingga akan mulai terbentuk uap air saturated maka didapat energi panas yang terbentuk pada uap saturated berdasarkan persamaan (8) didapatkan kalor yang dihasilkan oleh air umpan saat mejadi uap air sebesar 2022368,417 kWatt. Sementara itu didapat besar panas laten dari air sebesar 10184888,492 kWatt

Setelah terbentuk uap saturated makan akan masuk ke superheater untuk di rubah menjadi uap kering yang siap digunakan untuk proses kolom pada furnance di kilang,besar perpindahan panasnya adalah 2229663.996 kWatt dengan kondisi tekanan 3 bar. Oleh sebab itu didapat panas yang hilang dari bahan bakar sebesar 1709679,095kwatt.

\subsection{Kerugian Eksergi pada Boiler Wanson 1}

\subsubsection{Kerugian Eksergi pada Combustor}

Perhitungan kerugian eksergi pada combustor dihitung menggunakan persamaan (9). Diasumsikan pengoperasian combustor dalam keadaan steady sehingga tidak ada perubahan eksergi dalam berjalannya waktu. Perubahan laju aliran massa dan kontrol volume energi pada combustor dianggap nol. Kemudian juga diasumsikan gaya kinetik dan potensial pada combustor diabaikan.

Berdasarkan pada Tabel 6 laju alir massa bahan bakar adalah $0.04 \mathrm{~kg} / \mathrm{s}$, asumsi suhu $975 \mathrm{~K}$ menghasilkan perbandingan entalpi $39227 \mathrm{~kJ} / \mathrm{kg}$ dan entropi $1.56 \mathrm{~kJ} / \mathrm{kgK}$ berdasarkan perbandingan data dengan Tabel 4.

Tabel 6. Data untuk laju alir massa, suhu, entalpi, dan entropi berbasis DOSH (DOSH, 2009, REFPROP 7) [4].

\begin{tabular}{|c|c|c|c|c|c|}
\hline No. & Subtances & Mass flow rate $\mathrm{kg} / \mathrm{s}$ & Temperature ${ }^{\circ} \mathrm{C}$ & Enthalphy kj/kg & Entropy $\mathbf{k j} / \mathbf{k g}^{\mathbf{0}} \mathrm{C}$ \\
\hline 1. & Air & 4.125 & 126.85 & 400.98 & 1,9919 \\
\hline 2. & Fuel & 0.275 & 1243.99 & $50,050.00$ & 2.0 \\
\hline 3. & Hot products & 4.40 & 250 & 3504.00 & 7.0716 \\
\hline 4. & Water & 4.22 & 100 & 419.15 & 1.307 \\
\hline 5. & Steam & 4.22 & 185.334 & 2782.73 & 6.546 \\
\hline 6. & Flue gas & 4.40 & 212.57 & 361.44 & 1.9 \\
\hline
\end{tabular}


Nilai laju alir massa udara berdasarkan Tabel (2) $4.58 \mathrm{~kg} / \mathrm{s}$ dengan suhu $343^{\circ} \mathrm{C}$ mendapatkan nilai entalpi sebesar $623.854 \mathrm{~kJ} / \mathrm{kg}$ dan entropi $1.56 \mathrm{~kJ} . \mathrm{kgK}$. Nilai laju alir massa hot product pada Tabel (3) adalah sebesar $0.55 \mathrm{~kg} / \mathrm{s} . \mathrm{Hot}$ product memiliki suhu operasi $139^{\circ} \mathrm{C}$ sehingga mendapatkan nilai entalpi $2737.045 \mathrm{~kJ} / \mathrm{kg}$ dan nilai entropi sebesar 7.0199 kJ/kg.K. Maka berdasarkan persamaan (9) nilai kerugian eksergi pada combustor sebesar 1148.1627 kJ/s.

\subsubsection{Kerugian Eksergi pada Heat Exchanger}

Perhitungan kerugian eksergi pada heat exchanger seperti pada dasar teori persamaan (11). Dengan menggunakan asumsi yang sama dengan perhitungan kerugian eksergi pada combustor, maka perhitungan kerugian eksergi pada heat exchanger adalah $672.126 \mathrm{~kJ} / \mathrm{s}$.

\subsubsection{Total Kerugian Eksergi pada Boiler}

Total kerugian Eksergi pada combustor dan heat exchanger seperti pada persamaan (13) sebesar $1820.286 \mathrm{~kJ} / \mathrm{s}$.

\subsection{Efisiensi Eksergi pada Boiler}

\subsubsection{Efisiensi Eksergi pada Combustor}

Nilai efisiensi combustor didapatkan dengan membandingkan nilai laju alir massa hot product, entalpi hot product, dan entropi hot product dengan nilai laju alir massa bahan bakar, entalpi bahan bakar, dan nilai entropi bahan bakar. Efisiensi eksergi pada combustor didapatkan dengan persamaan (10) sebesar 22.88\%.

\subsubsection{Efisiensi Eksergi pada Heat Exchanger}

Perhitungan efisiensi eksergi pada heat exchanger berdasarkan persamaaan (12) adalah sebesar 44.21\%

\subsubsection{Efisiensi Eksergi pada Boiler}

Efisiensi eksergi secara keseluruhan pada boiler Wanson dapat dihitung sebagai berikut sesuai dengan persamaan (14) sebesar $13.29 \%$.

\section{Kesimpulan}

Dari hasil analisis besar perpindahan panas di lorong api kita dapat mengetahui daerah yang terjadi penumpukan kalor dan besar kalor yang terbuang dari proses perpindahan panas yang disebabkan oleh faktor-faktor penghambat seperti terbentuknya kerak pada dinding dinding luar dari pipa api boiler wanson. Dengan mengetahui hal tersebut kita dapat melakukan langkah maintenance secara preventive agar boiler bisa bekerja secara maksimal. Dari hasil perhitungan neraca panas dapat mengetahui apakah efisien kerja boiler tersebut dalam keadaan normal atau telah berada dibawah standard efisiensi yang baik.efiseinsi boiler yang baik menurut beberapa literature adalah sebesar $70 \%$.

Analisis Eksergi digunakan untuk mengetahui nilai eksergi yang terbuang pada setiap proses perubahahan panas atau energi disetiap komponennya sehingga kita bisa memfokuskan usaha atau kebijakan untuk meningkatkan efisiensi pada boiler. Kemudian pada analisis eksergi bisa membandingkan suatu komponen atau sistem untuk membantu memberi informasi pembuatan desain atau sistem yang tepat untuk suatu pengolahan. Hasil analisa kerugian eksergi pada combustor didapatkan sebesar $1148.16 \mathrm{~kJ} / \mathrm{kg}$ dengan efisiensi eksergi $22.88 \%$. Sedangkan untuk nilai kerugian eksergi pada heat exchanger adalah 672.126 kJ/s dengan efisiensi eksergi heat exchanger 44.21\%.

\section{Ucapan Terima Kasih}

Penulis mengucapkan terimakasih kepada PPSDM Migas Cepu dan Departemen Teknik Mesin Universitas Diponegoro atas dukungan dan bimbingan dalam penyusunan penelitian ini.

\section{Daftar Pustaka}

[1] UNEP, 2008, Boiler \& Pemanas Fluida Thermis: United Nation Environment Program.

[2] Winarto, S., 2010, Penghematan Energi pada Sistem Boiler, Jurnal forum teknologi, Vol. 04, No. 2, Hal. 35.

[3] Soomro, K.A., 2015, Central Power Generation CO. Ltd Genco-II, Guddu: Advance Operation Course.

[4] Saidur, dkk.,2009, Energy,Exergy and Economic Analysis of Industrial Boiler, ELSEVIER.

[5] Priangkoso, T., 2015, Analisa Perpindahan Kalor Pada Lorong Api Pada Lorong Ketel Uap, Momentum.

[6] Moran, M.J., Shapiro, H.N., 2000, Termodinamika Teknik. Edisi 4. Jilid 1\&2. Terjemahan oleh Yulianto Sulistyo Nugroho. 2004. Universitas Indonesia: Erlangga

[7] Bejan, A., 1988, Advanced Engineering Thermodinamics. Wiley, New York: Wiley.

[8] Adibhatla, S., Kaushik, S.C., 2014, Energy and exergy analysis of a supercritical thermal power plant at various load conditions under constant and pure sliding pressure operation, Applied Thermal Engineering 73, hal. 51-65.

[9] Holman, J.P., Jasfi, E., 1988, Perpindahan Kalor, Erlangga, Jakarta.

[10] Fox, R.W., Mc Donald, A.T., Pritchard, P.J., 2010, Introduction to Fluid Mechanics, 7th Edition. New York: John Wiley \& Sons. 